\title{
An assessment of university students and staff perceptions regarding the use of human urine as a valuable soil nutrient in South Africa
}

\author{
Mugivhisa L.L, Olowoyo, J.O
}

Department of Biology, Sefako Makgatho Health Sciences University, P.O Box 139, Medunsa, 0204, South Africa

\begin{abstract} the fertilizing effect of urine. urine for agricultural purposes could become more acceptable to people.

Keywords: Urine, crops, fertilizers and education

DOI: http://dx.doi.org/10.4314/ahs.v15i3.39

\section{Introduction}

One of the major challenges in developing countries is the need to continually increase food production so that it is always sufficient to feed the ever growing population ${ }^{1}$. In South Africa, an estimated 1.5 million children suffer from malnutrition with 14 million people being vulnerable to food insecurity with the emphasis on food insecurity more especially for the poor being placed on agriculture ${ }^{2}$. However, widespread declines in soil fertility associated with the indiscriminate application of unbalanced commercial fertilizers and the fail-
\end{abstract}

Background: The declines in soil fertility associated with insufficient commercial fertilizers have resulted in the use of organic manure (human urine and faeces) as a source of fertilizers for production and cultivation of crop plants. The aim of this study was to assess perceptions of students and workers at the University of Limpopo (Medunsa Campus) regarding

Methods: A total of 225 questionnaires were administered to staff and students. The questionnaire sought to establish the knowledge, attitude and behavioural changes as regards the use of urine as a fertilizer for the cultivation of vegetables.

Results: Descriptive statistical analysis of the data indicated that $86.8 \%$ of the respondents were unaware of any human urine use as a fertilizer, $82.7 \%$ and $81.1 \%$ would not eat spinach and maize fertilized with urine respectively. Only $38.3 \%$ said they would eat vegetables fertilized with animal urine making it more tolerable as compared to human urine. Health reasons were given as the main reasons why respondents were unwilling to eat crops fertilized with human urine. However, $69.9 \%$ of the respondents $[74.3 \%$ females, $69.9 \%$ students, $75.0 \%$ (27-36) age group] were willing to change their attitudes and unwillingness if they were better informed about the safety of human urine use for agricultural purposes.

Conclusion: Education, awareness and reassurance on the importance and safety of urine would have to be done so that

Cite as: Mugivhisa LL, Olowoyo JO. An assessment of university students and staff perceptions regarding the use of human urine as a valuable plant nutrient in South Africa. Afri Health Sci. 2015;15(3):999-1010. doi: bttp:// dx.doi.org/10.4314/abs.v15i3.39

\footnotetext{
Corresponding author:

Mugivhisa, L.L

Department of Biology,

University of Limpopo,

P.O. Box 139, Medunsa, 0204,

South Africa

E-mail: liziwe.mugivhisa@smu.ac.za,

Mobile Number: +27823536744,

Office Number: +2712 5213959
}

ure to provide sufficient fertilizers in many poor areas, have resulted in widespread decline in soil organic matter and reduced productivity of crops leading to hampering food production in many developing countries ${ }^{3}$. The cultivated soils including those used for subsistence farming in many parts of South Africa are also generally low in organic matter and bio-available phosphorus ${ }^{4}$.

Prices of chemical fertilizers have increased drastically globally contributing to $40 \%$ increase in food prices 5 . This increase of fertilizer prices has made conventional agricultural practices more difficult mainly for smallholder farmers in developing countries. The use of human urine as a fertilizer can assist with mitigation of poverty and multi-nutrition provision since it is a fertilizer that is freely available ${ }^{6}$. To overcome the problem of declining soil fertility and expensive fertilizers, methods of organic farming through the use of human urine and bio-solids have been considered as valuable substitutes for commercial chemical fertilizers. These agricultural practices making use of organic materials as sources of nutrients provide a viable alternative which is both environmentally friendly and sustainable? 
The limiting factors in plant growth are usually nitrogen, unfavourable soil and water conditions. ${ }^{8}$. Human urine is the most promising and appropriate product to be used for agricultural purposes since it contains relatively high concentrations of Phosphorus (P), Nitrogen $(\mathrm{N})$ and other nutrients like Potassium $(\mathrm{K})$ and micronutrients and hence can be utilized as a multicomponent mineral fertilizer. It can also be applied with ease manually or with conventional equipment at the farms ${ }^{9}$. In fresh human urine, nitrogen occurs as urea which is beneficial to plants and is often contained in commercial fertilizers ${ }^{8}$. Urine also contains water and a variety of organic and inorganic compounds as compared to solid mineral fertilizers ${ }^{10}$ and seldom contains elements which pose a high health risk even though it may contain high chloride contents ${ }^{8}$. It is a quick acting nitrogen-rich liquid fertilizer ${ }^{6}$.

Human urine has also been stated as a low-cost, high quality fertilizer ${ }^{11}$. From a study by Akpan-Idiok, ${ }^{11}$ comparing the fertilizing effects of dried chicken manure, meat + bone meal and urine on winter wheat, human urine was found to have the highest yield followed by dried chicken manure and then meat+bone meal. The fertilizing effect of human urine was also observed to be higher than that of mineral fertilizers for the production of barley in Germany ${ }^{11}$. In Ethiopia, the yields of Swiss chard which was fertilized with human urine were found to be four times more than those which were unfertilized and also in Zimbabwe the yields of vegetables which were fertilized with human urine were found to be higher than those that were unfertilized ${ }^{11}$.

The urine of a healthy individual is considered sterile in the bladder even though as it passes through different types of dermal tissues, bacteria are added to it resulting in less than ten thousand bacteria per $\mathrm{ml}$ being excreted with urine ${ }^{12}$. The pathogens which cause venereal diseases can also be excreted through urine but there is no indication of whether they have a potential to thrive outside the human body and if this would be of any health significance ${ }^{12}$. The drying of soil which results from evaporation from the plants can result in the decreased chances of survival of these pathogenic agents in the soil ${ }^{8}$.

In the European Union (laws on fertilizer products and organic farming) the legislation does not forbid or allow the use of human urine as a fertilizer ${ }^{13}$. A literature review which had been done revealed that internationally especially in China, the utilization of urine and faeces for production of food was an old practice, well known and accepted ${ }^{14}$. The human excreta and urine have been traditionally used as fertilizers in agriculture and in household gardens to increase yields and to economize on expensive inorganic fertilizer by the people of Vietnam especially in the Northern and Central provinces ${ }^{15}$. In Vietnam and Southern China farmers consider human excreta as "valuable fertilizer"16. Human urine is also being used as a source of nutrients for agricultural purposes in Mexico, Germany, USA, Sweden, Denmark and Zimbabwe ${ }^{3}$. In some African countries, the use of urine and faeces for food production has also been accepted. However, there is little or no information on its use in South Africa because of the lack of urine diversion (UD) toilets which enable the hygienic separation of urine and faeces. The recent introduction of UD toilets in South Africa should lead to an increase in the use of urine for agricultural purposes ${ }^{17}$.

The use and handling of human excreta such as urine for agricultural purposes is still foreign and generally not accepted as human excreta is regarded as waste products, unhealthy and detrimental to humans ${ }^{2}$. Personal prejudices and ethical issues have contributed to a decline in the popularity of using human urine as a source of fertilizers. Attitudes and perceptions with regards to the health hazards and peoples' disgust with human urine vary between cultures and also within specific cultures worldwide ${ }^{18}$. In the Karega area in Tanzania, urine is considered to have a disinfectant property ${ }^{2}$. The social attitudes with respect to the use of human excreta differ with age, marital status, sex, education, religion, class, locality and employment status. For example some people regard urine as a spiritual pollutant and hence reduce contact with urine for that reason ${ }^{14}$.

The fact that human excreta is used for agricultural purposes is practiced in some parts of Africa and internationally indicates that it is logical and acceptable from the point of view of users ${ }^{19}$. A better understanding of the social and motivational factors behind the acceptance or rejection of the use of human urine for agricultural purposes is required so that the fears and misconceptions of users can be addressed ${ }^{2}$. There is a need to overcome unwillingness of most South Africans to utilize human excreta as a fertilizer so that South Africans can utilize human excreta as a fertilizer and also so that the acceptance of technologies in ecological sanitation and food security can be strengthened ${ }^{2}$. People's 
attitudes and views towards human excreta need to be changed so that the solutions for ecological sanitation for food production can be achieved since many communities in South Africa rely on subsistence agriculture often in poor soils ${ }^{20}$.

The present study assessed the attitudes of students and workers at the University of Limpopo (Medunsa Campus) with respect to the use of human urine in the production and cultivation of crop plants. The objectives were to assess how often the respondents consumed cultivated plants (fresh vegetables, crops), how much they knew about the different types of fertilizers (compost, chemical and manure) and the type of fertilizers they preferred for growing their vegetables). The other objectives were to assess how much information the respondents had with respect to the nutritional value of the human urine and if they knew of any use of human urine as fertilizer in South Africa and also if they would eat spinach or maize fertilized with human urine or with animal urine. One of the main objectives was to assess if the respondents were willing to change their attitudes if they were well or better informed about the fears or concerns they had for unwillingness to eat plants fertilized with human urine. This study was designed to assess the hypothesis that lack of knowledge on the importance of human urine for agricultural purposes results in people finding its use as a valuable plant nutrient unacceptable.

\section{Materials and methods}

A total of 225 questionnaires were administered to the students and staff members at the University of Limpopo, Medunsa Campus situated in Pretoria in South Africa. The campus provides training facilities and tertiary education to the educationally disadvantaged students in the fields of medicine, dentistry, allied health and nursing sciences.

Information that was on the form and requested from the respondents included personal information (age, sex, level of education and occupation), nutritional information (frequency of eating fresh vegetables and frequency of eating crops( spinach and maize) separately, knowledge on fertilizer information [to check which type of fertilizers (compost, chemical and manure fertilizers) the respondents knew or were familiar with] and preference of a particular type of fertilizer by the respondents (if they would knowingly eat fresh vegetables fertilized with compost, chemical or manure fertilizers), fertilizing value of human urine (if the respond- ents were aware of the fertilizing value of human urine) and knowledge on the known usage of human urine as a fertilizer in South Africa, information on whether they would eat cooked spinach or maize fertilized with human urine and if not what the reasons (if reasons would be health reasons, witchcraft, religion, taboo or other reasons) would be and if they would maybe consider eating spinach and maize fertilized with animal urine and also if they would be willing to donate or sell urine for use in agriculture. The participants were also asked to indicate if they would consider changing their beliefs or perceptions if they were better or well informed about the use of human urine for agricultural purposes.

The choice of a sample was mainly done for convenience, mainly targeting the first year, third year and postgraduate students in the departments of Biology and Chemistry. Staff members mainly the academic and administration staffs were also from the Biology and Chemistry departments and this was also due to convenience. Other staff members who were selected were the general workers (cleaners). The convenient sampling methods were based on the nature of the University. The University is a medical school with a very small number of students and staff. In most cases, the medical students are often very difficult to get due to their busy schedule which also includes being at the academic hospital and not on campus during their clinical studies. A greater percentage of students that are enrolled for medical degrees graduated from the basic science field from the same university. Hence, the view and beliefs of the students currently enrolled as medical students might have not changed since they were former science students within the same university. Statistical analyses in the form of quantitative analyses such as tables and graphs were used to analyze the data.

\section{Results}

From the 225 respondents, $66.7 \%$ were females and $33.3 \%$ were males. The majority of the respondents were students with $84.1 \%$ followed by the academic staff with $7.9 \%$, general workers with $6.2 \%$ and administrative staff with $1.8 \%$. The age group of the majority of respondents was $18-26$ years with $88.8 \%$ of the respondents in that age group being students with the rest of the other age groups having only $0.04 \%$ of the respondents each.

The percentages of the respondents with respect to the consumption of fresh vegetables crops are represented in Table 1. Only $25.7 \%$ of the respondents indicated 
that they ate fresh vegetables daily, 53.7\% weekly, $19.7 \%$ at least once per month and $0.9 \%$ mentioned they never ate fresh vegetables. With respect to spinach, 73.2\% of the respondents mentioned that they ate spinach at least once a month, $3.9 \%$ daily, $15.1 \%$ once a week and $7.8 \%$ saying they did not eat spinach at all. For maize the percentages of respondents consuming maize daily, weekly, monthly and never were $26.9 \%, 36.6 \%, 35.7$ and $0.9 \%$ respectively.

Table 1: The percentages of the respondents with respect to their consumption of food and crops.

\begin{tabular}{|lcccc|}
\hline Food Consumption & Daily & Weekly & Monthly & Never \\
Fresh vegetables & $25.7 \%$ & $53.7 \%$ & $19.7 \%$ & $0.9 \%$ \\
Spinach & $3.9 \%$ & $15.1 \%$ & $73.2 \%$ & $7.8 \%$ \\
Maize & $26.9 \%$ & $36.6 \%$ & $35.7 \%$ & $0.9 \%$ \\
\hline
\end{tabular}

Results for the familiarity of the fertilizers to the respondents and the most preferred type of fertilizers by the respondents are indicated in Figure 1 and Figure 2 respectively. Most of the respondents $(57.3 \%)$ were familiar with manure as fertilizers, as compared to $24.6 \%$ and $18.1 \%$ being familiar with chemical fertilizers and compost respectively (Figure 1). Similarly the number of respondents who preferred to eat fresh vegetables which had been fertilized with manure was also much higher at $60.2 \%$ compared to $15.7 \%$ and $24.1 \%$ who preferred food fertilized with chemical fertilizers and compost respectively indicating that respondents preferred the types of fertilizers on the crops based on their familiarity with those fertilizers.

\section{Figure 1. The different types of fertilizers which are common to the respondents.}

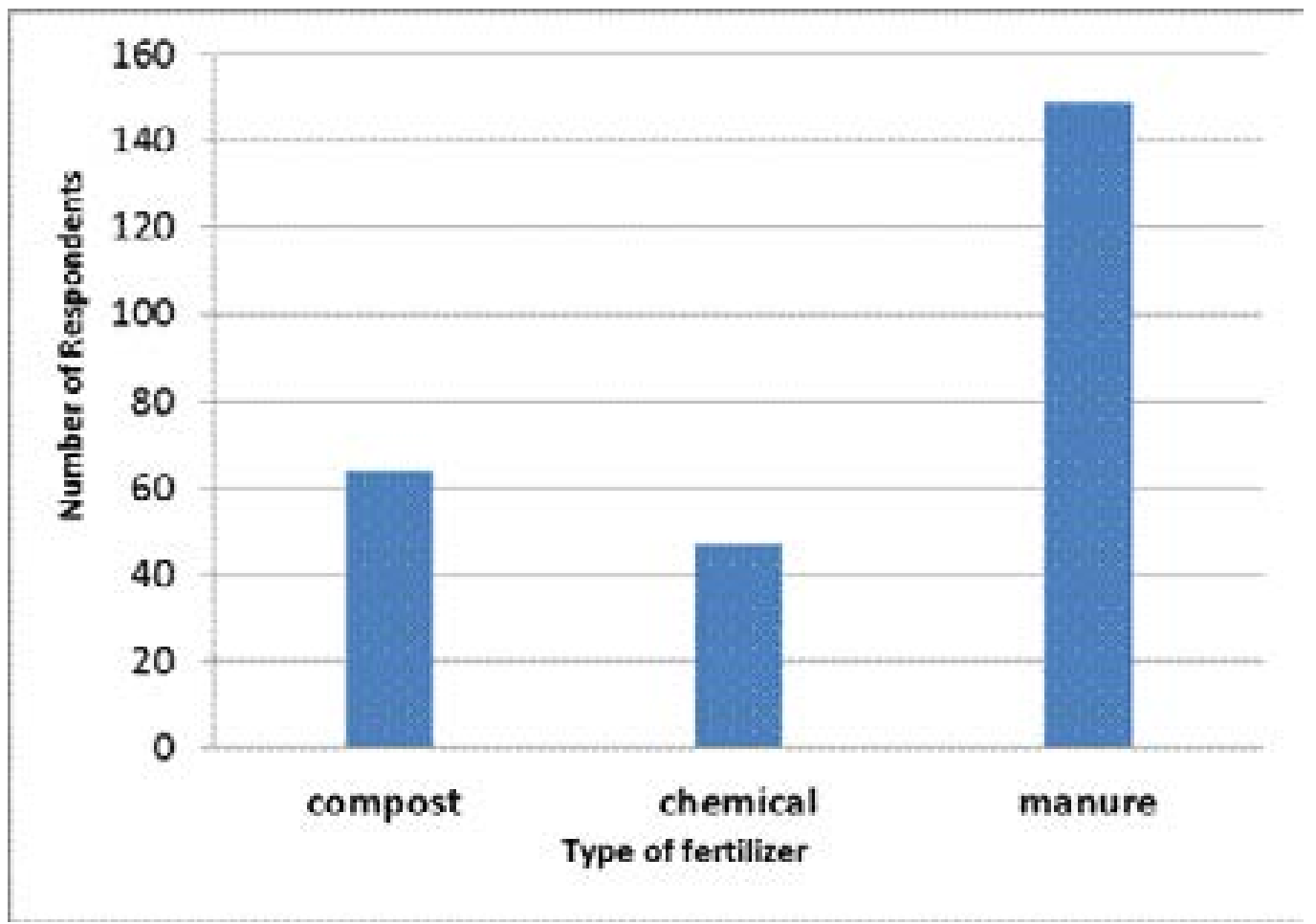


Figure 2. The different types of fertilizers preferred by the respondents for fertilizing the crops.

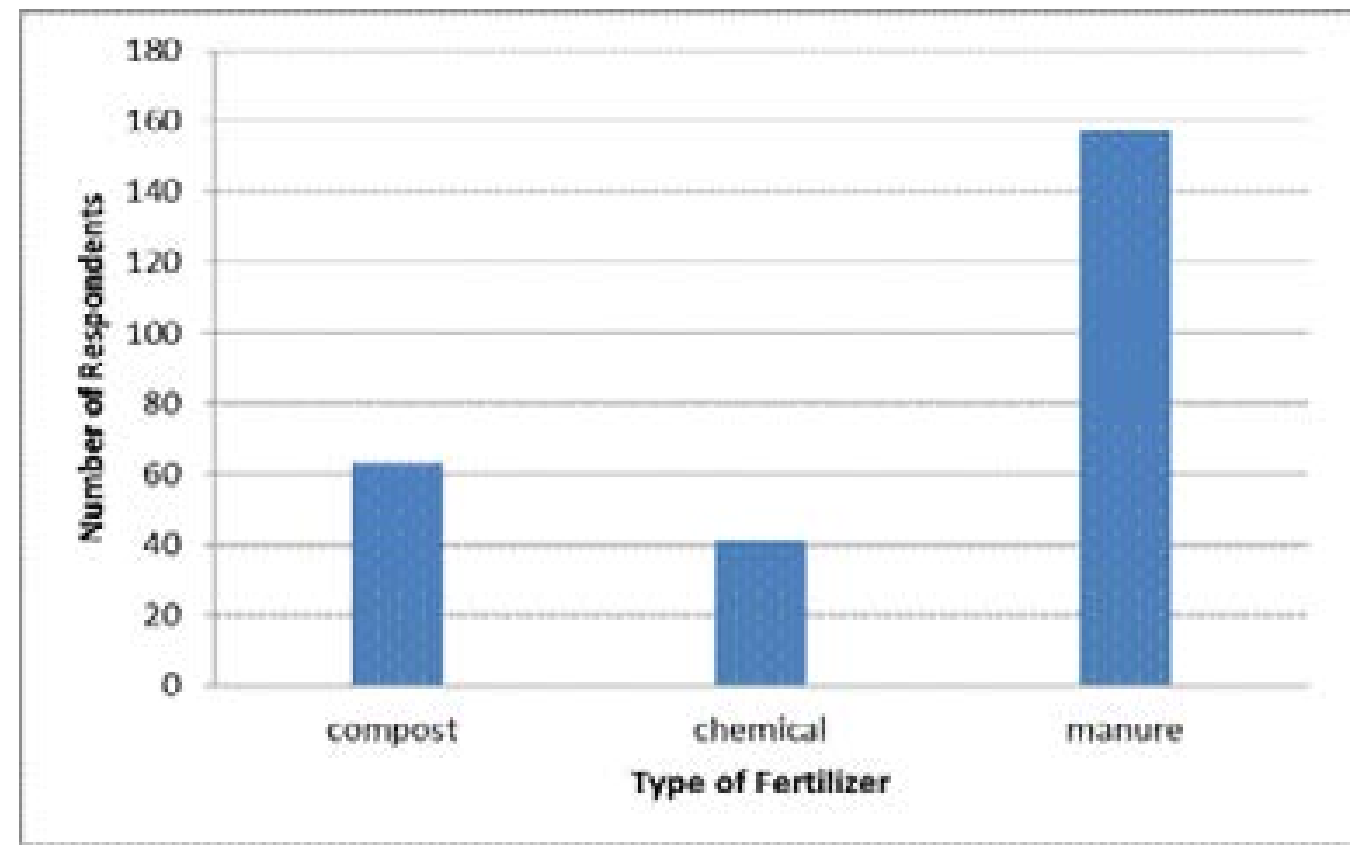

Figure 3 indicates that only $23.6 \%$ of the respondents were aware of the fertilizing value of human urine with $73.7 \%$ saying that they had no awareness of the fertilizing value of the human urine. In comparison there was less awareness of the use of human urine as a fertilizer from the study group with only $13.2 \%$ being aware and $86.8 \%$ not aware of the use of human urine as a fertilizer from the study group. The respondents who said they were willing to eat spinach fertilized with human urine were less than those who were willing to eat maize fertilized with human urine with $17.3 \%$ and $18.9 \%$ respectively as compared to $82.7 \%$ and $81.1 \%$ who were not willing to eat spinach and maize fertilized with human urine respectively. The number of respondents willing to eat plants fertilized with animal urine increased slightly to $38.3 \%$ and this was much higher compared to the above mentioned lower numbers saying they would eat spinach and maize fertilized with human urine.

Figure 3. Different responses and attitudes given by the respondents.

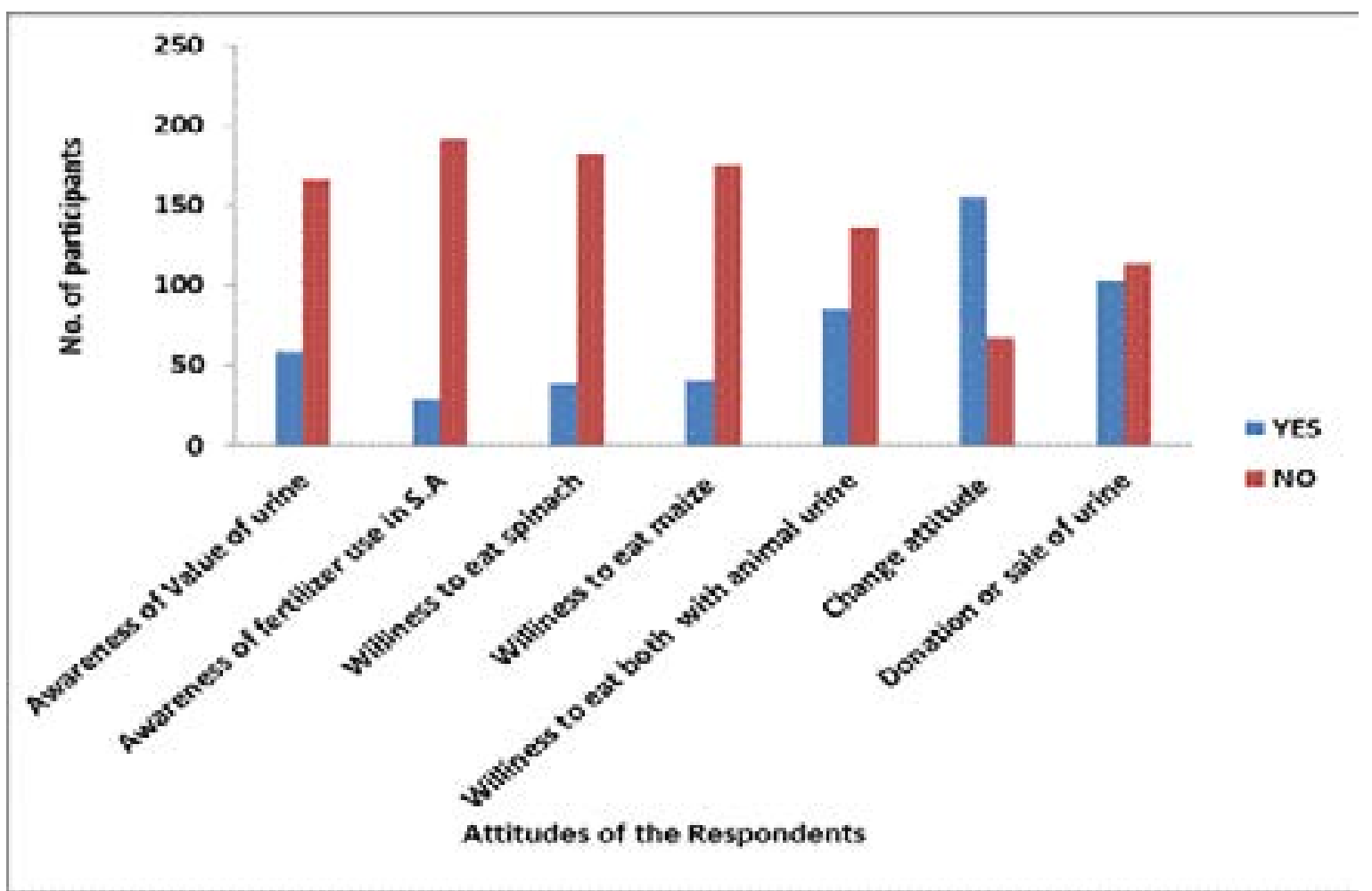


Figure 4 indicates that $66.0 \%$ of the respondents gave health reasons as the main reason for unwillingness to eat spinach fertilized with human urine as compared with only $1.0 \%$ of them giving religion as the main reason.

Figure 4. Reasons of the respondents for unwillingness to eat Spinach fertilized with Human Urine.

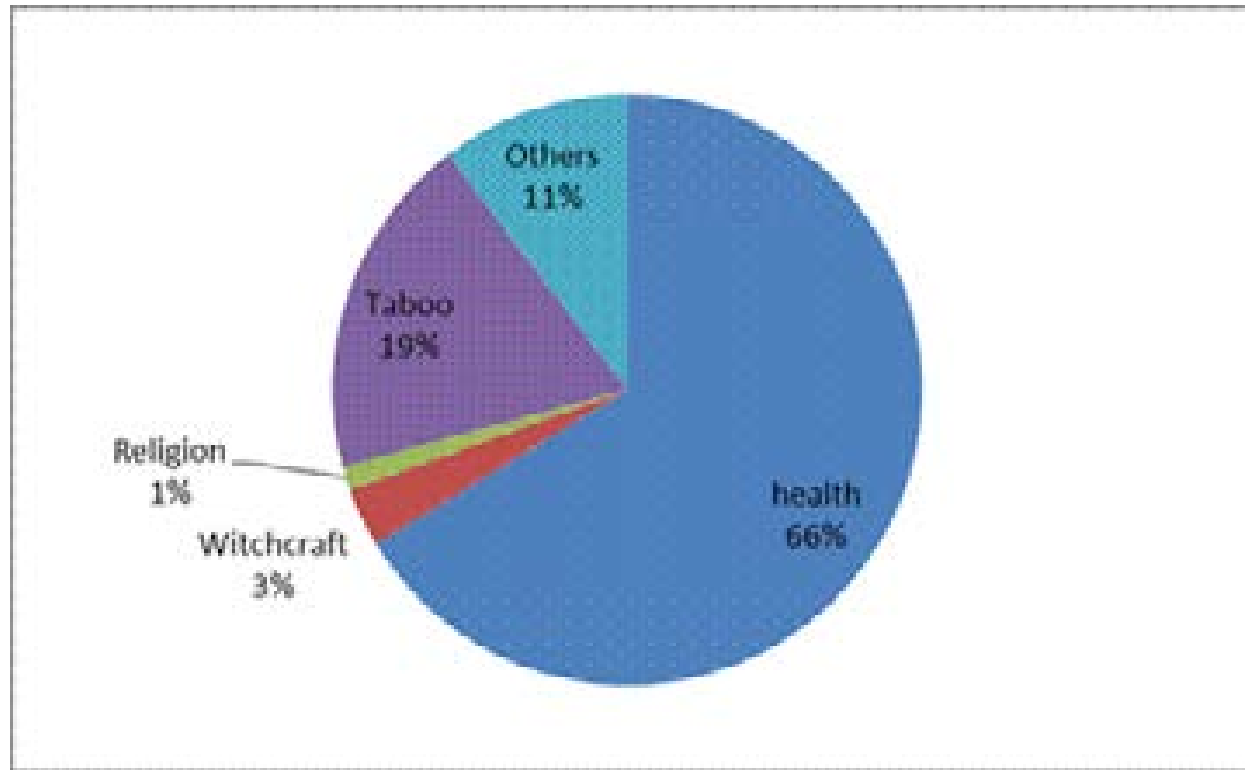

For maize as indicated in Figure 5, 7.0\% of the re- The second most common reason for unwillingness to spondents gave health reasons as the main reason for eat crops fertilized with human urine was that it is a not willing to eat maize fertilized with human urine as taboo and a couple of respondents responded that it compared to $2.0 \%$ giving religion as the main reason. is disgusting'.

\section{Figure 5. Reasons of the respondents for unwillingness to eat Maize fertilized with Human Urine.}

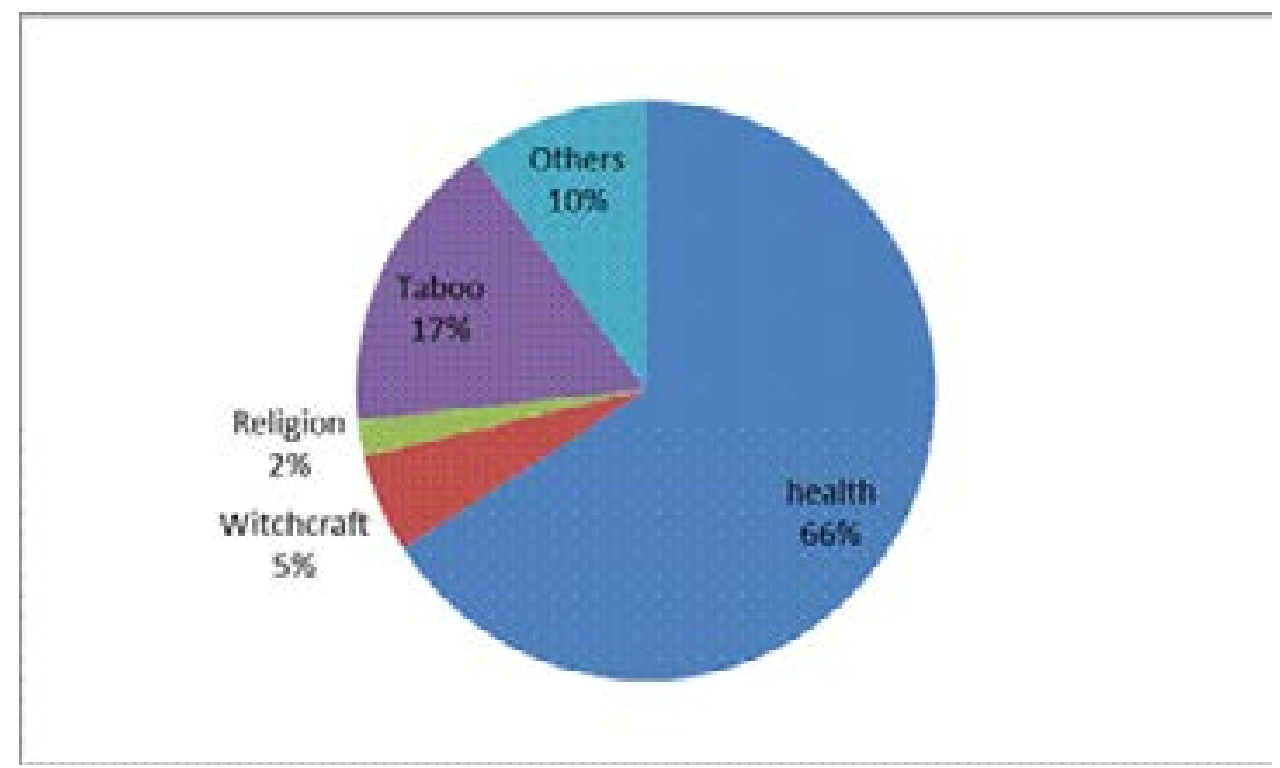

Even though most of the respondents indicated that they would not eat crops fertilized with human urine or any plants fertilized with animal urine there was a big increase in the number of respondents with $69.9 \%$ saying they would change their attitudes and perceptions about willingness to eat crops fertilized with human 
urine if they were better informed about the effects and safety of consumption of human urine for agricultural purposes as compared to only $30.2 \%$ of the respondents saying they would not consider changing their minds even if they were better informed. There was no significant difference between $47.5 \%$ who were willing to sell or donate urine for agricultural purposes and $52.5 \%$ who said they would not sell or donate urine for agricultural purposes.

The responses of the participants with respect to whether they would eat crops fertilized with human urine and whether they would change their attitudes based on gender, age, level of education and profession are represented in figures $6,7,8$ and 9 respectively. Figure 6 indicates that more males $(20.3 \%)$ and $(23.4 \%)$ responded that they were willing to eat spinach and maize respectively fertilized with human urine compared with $15.0 \%$ and $18.2 \%$ of females responding that they would not eat spinach and maize respectively fertilized with human urine. However more females $(74.3 \%)$ compared to males $(55.7 \%)$ were willing to change their attitudes if they were better informed about the consumption of human urine on crops. This differs from a study by Duncker and Matsebe ${ }^{20}$ in which females were the ones who had more opinions with regard to the use of human excreta compared to the males.

\section{Figure 6. Relationship between gender and responses of participants regarding whether they would consume crops fertilized with human urine and whether they would change their views if they were better informed.}

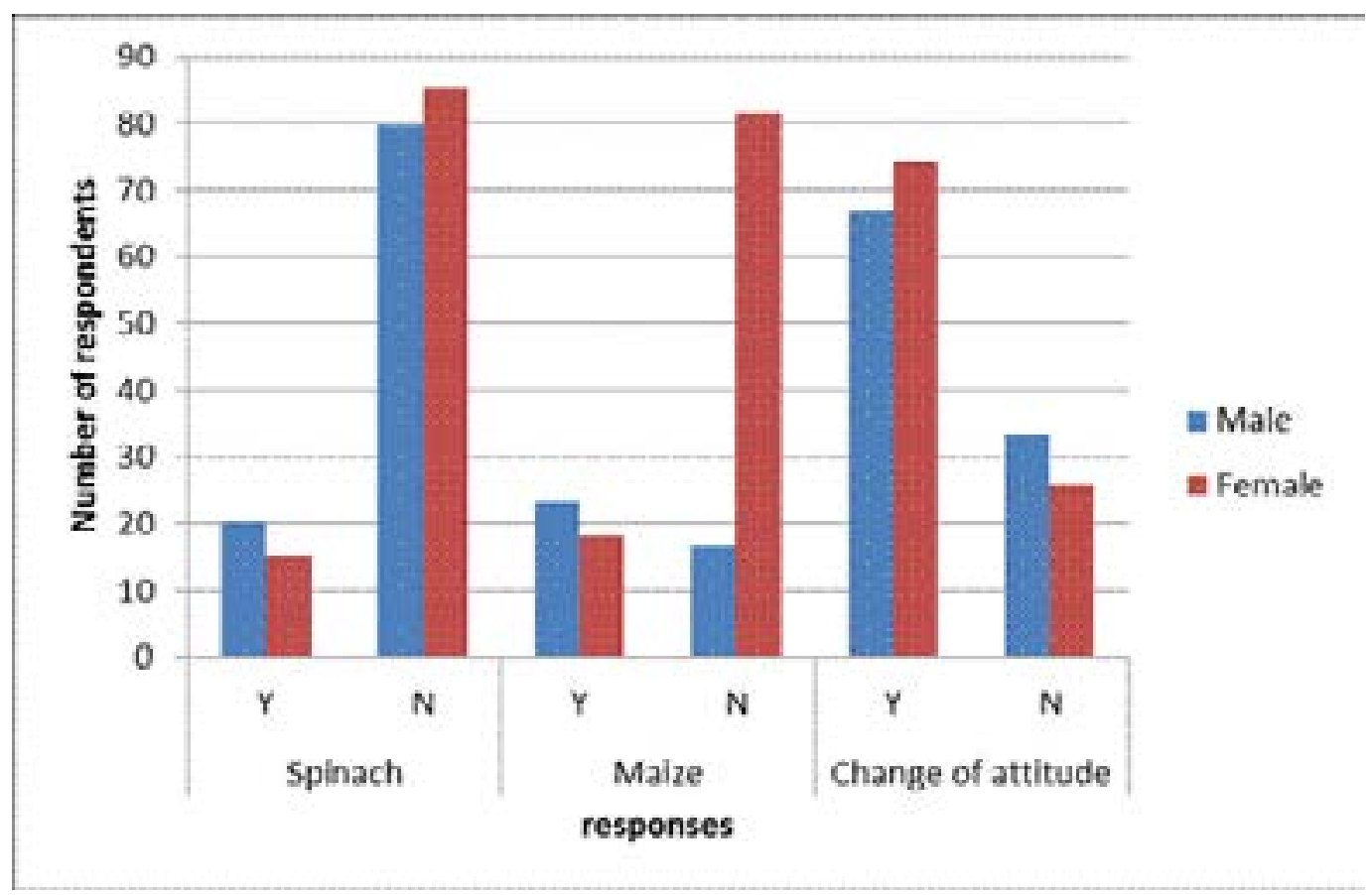

Figure 7 shows that none of the respondents without matric qualification were willing to eat any of the crops fertilized with human urine and $66.7 \%$ of those respondents were unwilling to change their attitudes even if they were better informed. The responses of respondents without matric differed significantly with the responses of those with matric with $17.8 \%$ and $19.0 \%$ willing to eat spinach and maize respectively fertilized with human urine. Respondents who had degrees and were willing to eat spinach and maize fertilised with human urine were $16.7 \%$ and $19.0 \%$ respectively. More of the respondents with matric $(71.3 \%)$ and degrees $(76.2 \%)$ being willing to change their attitudes if they were better informed. 
Figure 7. Relationship between age and responses of participants regarding whether they would consume crops fertilized with human urine and whether they would change their views if they were better informed.

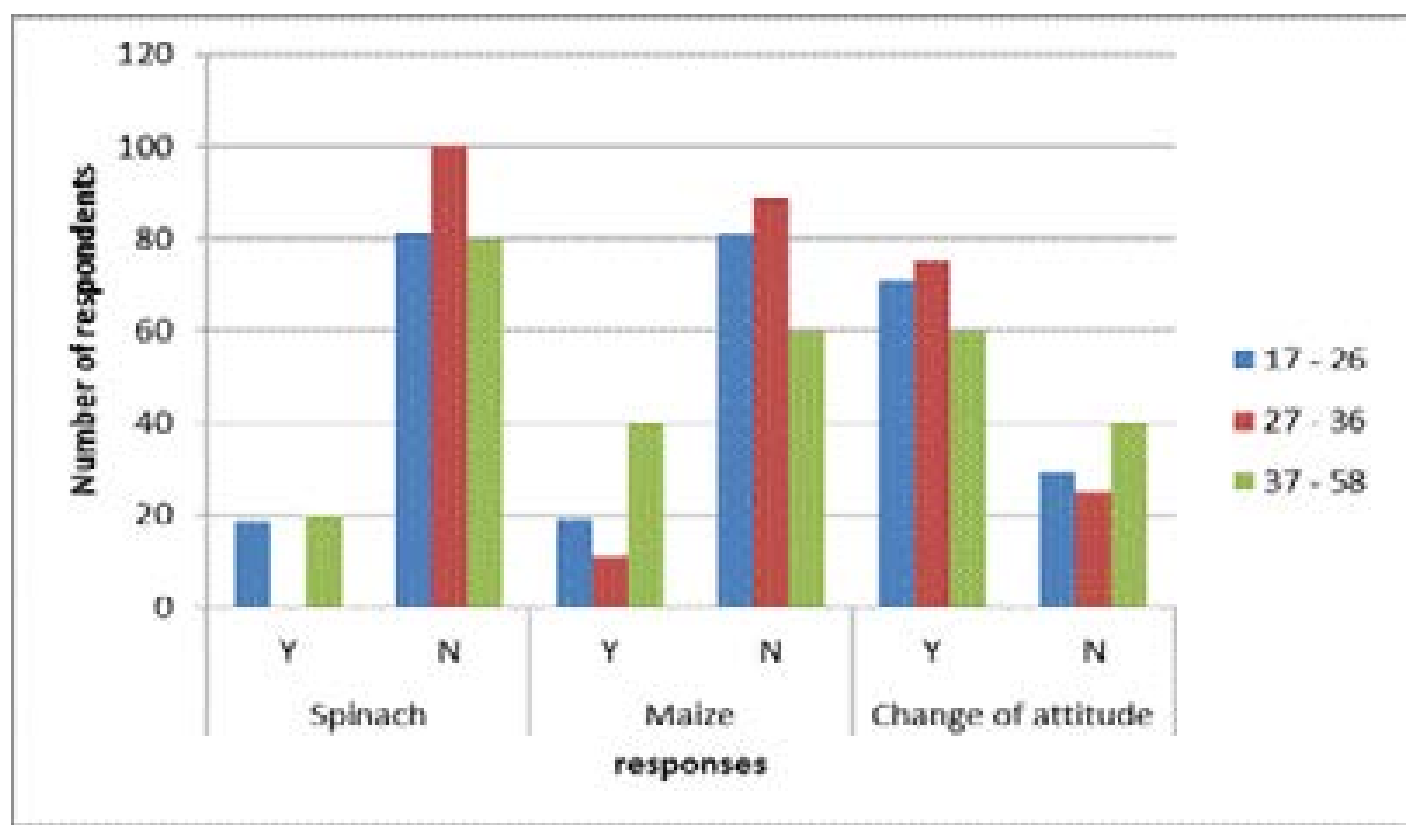

With respect to the age groups, figure 8 indicates that the respondents in the age group 27-36 consisting of more mature students were more intolerant to the con- sumption of crops fertilized with human urine with $100.0 \%$ and $88.9 \%$ not willing to eat spinach and maize fertilized with human urine respectively.

Figure 8. Relationship between the level of education and responses of participants regarding whether they would consume crops (spinach and maize) fertilized with human urine and whether they would change their views if they were better informed

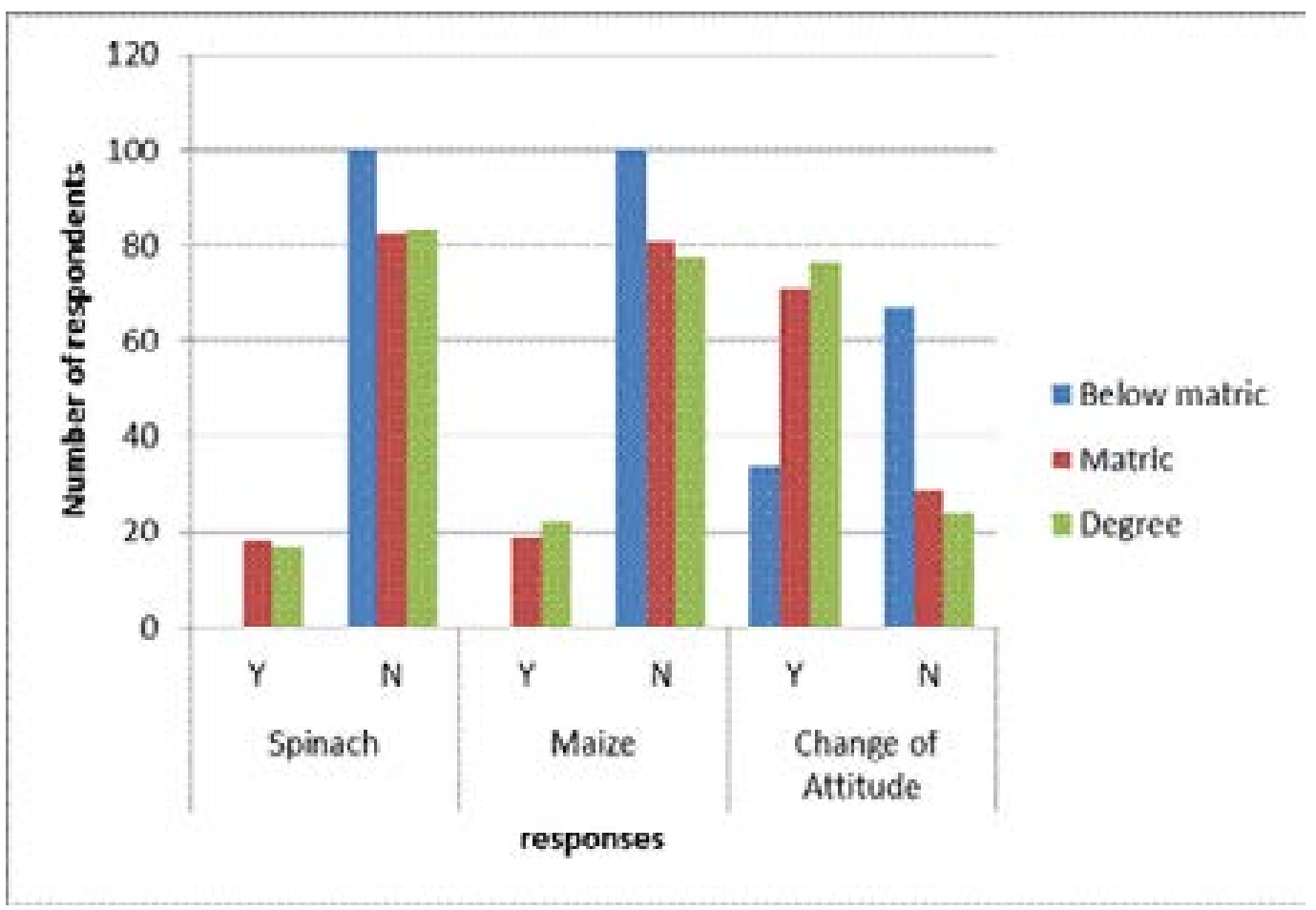


However $75.0 \%$ of them were willing to change their attitudes. The age group 37-58 was the least group with respondents willing to change their attitudes. Significantly more professionals $(25.0 \%$ and $45.6 \%)$ respectively responded that they would eat spinach and maize fertilized with human urine compared to the students $(17.5 \%$ and $18.2 \%)$ respectively who responded that they were willing to eat the spinach and maize. A much larger group of students $(69.9 \%)$ compared to $(66.7 \%)$ of professionals responded that their attitudes would change if they were better informed.

\section{Figure 9. Relationship between the profession and responses of participants regarding whether they would consume crops fertilized with human urine and whether they would change their views if they were better informed.}

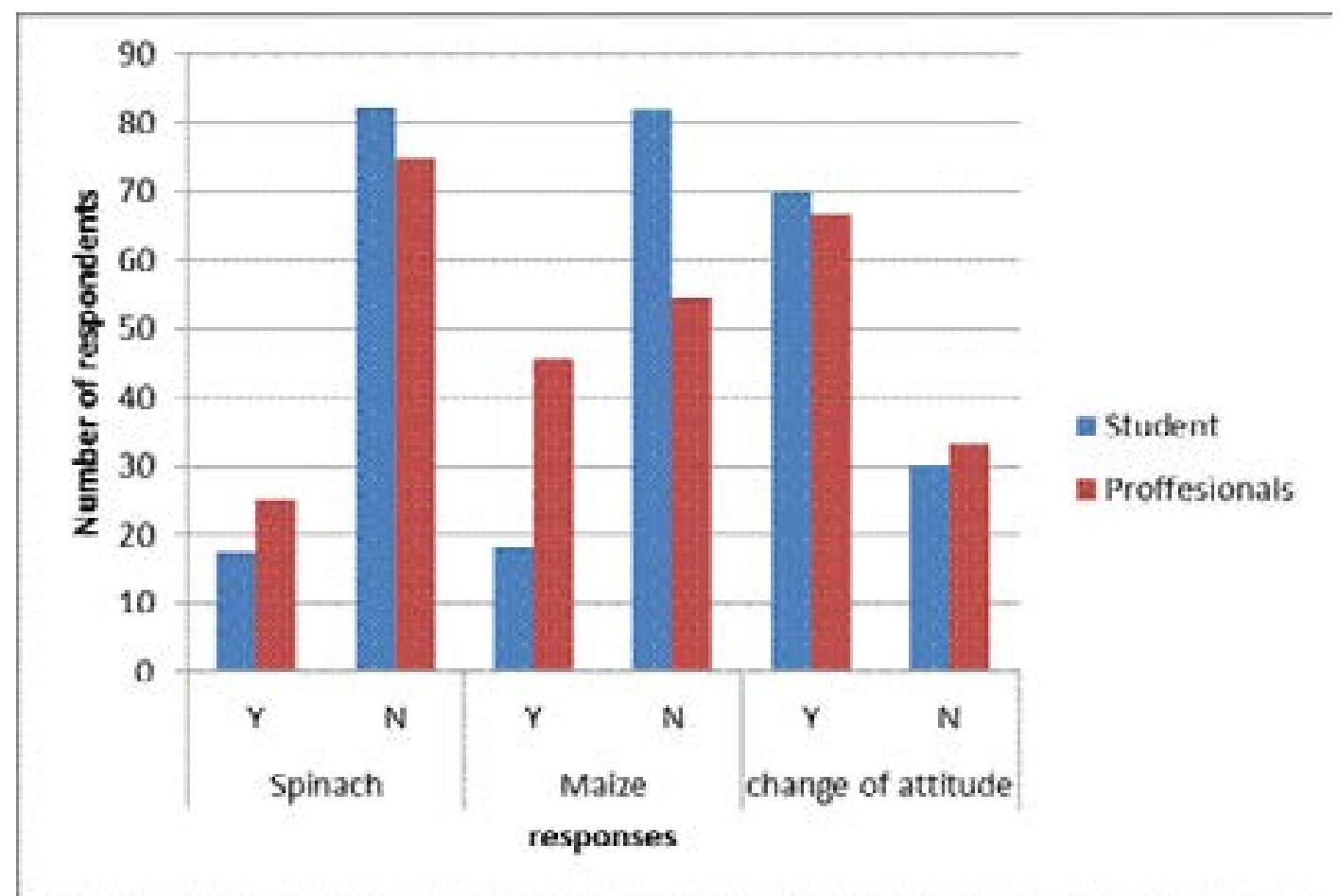

\section{Discussions}

The majority of the respondents who took part in the study were the students in a tertiary institution who fell in the younger age group. This young group of students who were not willing to eat crops fertilized with human urine might not see the importance of agriculture or use of human urine for growing vegetables as compared to older people (general workers) and rural communities who might know the importance of using natural resources for growing plants. The results also indicated that the more mature age group (27-36) were the ones who were more intolerable to eating crops fertilized with human urine than the much younger students (17-26) and older respondents.

More females took part in the study but that was due to the demographics. This corresponds with the larger number of females than males in Duncker and Matsebe $^{20}$ in which the gender split was $75.0 \%$ females and $25.0 \%$ males since females were readily available during the day as most did not have day jobs compared to the males when the study was carried out. The main difference between the present study and Duncker and Matsebe ${ }^{20}$ is in the responses given by females who were more unwilling to eat crops fertilized with human urine than the males in the present study compared to Duncker and Matsebe ${ }^{20}$ in which men did not have much opinion with respect to the consumption of human excreta on crops as traditional gender roles were still practiced and women were regarded to be more involved in sanitation issues than men. Also in Dunker and Matsebe ${ }^{20}$, the female participants in general had a higher level of knowledge of fertilizer value of human excreta and value of human urine medicinally as compared to the male respondents.

All respondents without matric qualifications were unwilling to eat both spinach and maize which were fertilized with human urine compared to those who had matric and degrees. The less educated respondents also 
indicated they were more unwilling to changing their attitudes even if they were better informed about the use of human urine for agricultural purposes. This could have been that the less educated people usually resist change and do not believe that any form of change can be good or beneficial whereas the more educated believe that research and newer innovations can improve the quality of life.

Most of respondents being students, did not consume fresh vegetables, spinach or maize on a daily basis as most of the food the students consume is mainly junk food as the preparation of vegetables would require more time and work for preparation. The nutritional responses of the respondents did not seem to match with their perceptions and attitudes on the use of human urine for agricultural purposes.

Respondents preferred to eat food which was fertilized with the fertilizers they were familiar with and that could have also contributed to why they responded that they were not willing to eat crops which had been fertilized with human urine as the respondents indicated in the study that they were not familiar with the use of human urine as a fertilizer.

In the present study as compared to the study by Cofie et al, ${ }^{21}$ the majority of the respondents were unaware of the possibility of human urine use in agriculture. In the study by Cofie et al, ${ }^{22}$ most of the respondents regarded urine as an agricultural innovation which was good and one respondent even claimed she had never fallen sick from eating vegetables which had been fertilized with contents of old pit latrines. The present study also differs greatly from the responses which were given by farmers in a study in Accra in Ghana in 2006 by Cofie et al., ${ }^{21}$ in which $82.0 \%$ of the farmers did not approve of the disposal of human urine as municipal waste as they believed there were plant nutrients available in urine that could be used for the production of vegetables. Only $12.0 \%$ of the farmers said human urine was of no use and had to be disposed off as municipal waste.

With respect to the knowledge of the respondents, the responses of participants in the present study compared similarly to those in studies which were done by Benoit $^{23}$ and Duncker ${ }^{19}$ in Ethekwini, South Africa, in which few of the respondents had some knowledge of the fertilizing potential of faeces but not on the fertilizing potential of human urine and also similarly to the study by Drangert and $\mathrm{Nawab}^{24}$ in which the respond- ents were not aware that most of the plant nutrients were in the urine and not in the faeces. In comparison to the international studies, for example in a survey which was carried out on Swiss farmers by Lamichhane et $\mathrm{al}^{25}$ there is a difference between the responses in that $57.0 \%$ of the farmers accepted the urine based fertilizer and $42 \%$ were in favour of buying the products fertilized by urine whereas in the present study the majority of the respondents were not willing to use human urine as fertilizers.

In the present study, more respondents said they were willing to eat vegetables fertilized with animal urine as compared to those who said they would eat crops fertilized with human urine. This shows a slight increase in tolerance of animal urine as compared to human urine.

There was a higher percentage of respondents saying they would not eat plants fertilized with human urine in the present study in contrast with another similar study which had also been done by Duncker et al, ${ }^{2}$ on the Social / Cultural Acceptability of Using Human Excreta (Faeces and Urine) for Food Production in Rural Settlements in South Africa in which more respondents were willing to eat vegetables fertilized with human urine. This could be attributed to the fact that in an academic institution, respondents were in an urban environment and did not practice agriculture as compared to those who were in the rural environments and hence benefited directly from growing their own vegetables.

Whether it was maize or any vegetables, the respondents in the present study felt that it was not acceptable to eat either of them fertilized with human urine whereas in the study by Cofie et al, ${ }^{21}$, the respondents did not have specific type of plants onto which urine could be used as a fertilizer even though respondents said the use of excreta on maize was more acceptable as compared to the use on other vegetables.

The main reason given by the respondents in the present study for unwillingness to use human urine for agricultural purposes was that it was unhealthy and this could be due to the fact that urine is seen as a waste product. However $20.0 \%$ and $26.0 \%$ of the farmers and consumers respectively in the study by Cofie et al, ${ }^{21}$ gave cultural norms and $38.0 \%$ of consumers and $26.0 \%$ of the farmers gave specific religious objections as constraints to use of urine in agriculture. The other responses that were given by the participants were that $48 \%$ thought the urine would kill the plants, $14.8 \%$ 
thought it would kill the insects, $4.0 \%$ thought it would pollute the soil and only $9.7 \%$ thought it would assist the plants to grow better. The results of the survey carried out by WRC ${ }^{14}$, also indicated that physical handling of human excreta was not normal because it was unhygienic. The findings of $\mathrm{WRC}^{14}$ also correspond with the reasons which were given by the respondents in the present study. In contrast to the present study in which the majority of the respondents were unwilling to eat vegetables fertilized with human urine, the respondents in the study by WRC ${ }^{14}$ said they would use the human excreta in gardens and eat the food produced with human excreta.

The respondents in the present study indicated that they were willing to change their beliefs about the unacceptability of human urine use in agriculture if they were better informed. This corresponds with results in the study by Cofie eet $\mathrm{al}^{21}$, in which the respondents revealed that they were open to changing their minds and they believed that their fears or concerns about health risks could be mitigated by educating them on the precautionary measures which could be taken when applying the excreta on plants.

\section{Conclusion}

The fact that in the present study, respondents indicated that they were willing to change their attitudes if they were better informed indicates that in-depth studies of the factors which are important in changing people's views with regard to the use of human excreta for food production can be of great value. People should be well informed and educated about the human excreta as a useful resource, as a threat to health if it is not done properly, about the benefits and consequences if any of the use of human urine for agricultural purposes. The main aspect that has to be addressed is its safety and healthiness for agricultural purposes. There is a need to prove and guarantee that no diseases can be borne from the human urine which has been used to fertilize the plants. More research has to be done to educate people about the importance of reuse and recycling of the human wastes for agricultural purposes. There could be laws implemented about the use of human waste products such as urine for agricultural purposes and granting of permits for application of human waste products on plants so that people could feel at ease with their use for agricultural purposes.

\section{Acknowledgements}

The authors would like to thank all the staff and stu- dents of the University of Limpopo (Medunsa Campus) who took part in the study.

\section{References}

1. Akpan-Idiok, A.U., Udo, I.A., Braide, I.E. (2012). The use of human urine as an organic fertilizer in the production of okra (Abelmoschus esculentus) In South Eastern Nigeria. Resources, Conservation and Recycling 62: 14-20.

2. Benoit, N. 2012. Individual's perceptions and the potential of urine as a fertilizer in Ethekwini, South Africa. Unpublished Masters Diss., University of KwaZulu Natal.

3. Caldwell, I., Rosemarin, A. 2008. Human urine and faeces as a fertilizer. Stockholm Environment Institute Environment and Poverty Times 05.

4. Cofie, O., Adeoti, A., Nkansah-Boadu, F., Awuah, E. 2010. Farmers' perception and economic benefits of excreta use in Southern Ghana. Resources, Conservation and Recycling, 55: 161 - 166.

5. Cofie, O., Amoah, P., Egyir, I., Noah, A., Tettey-Lowor, F. 2011. Demonstration on the use of urine in urban agriculture. Sixth Framework Program (2002-2006). 018530 - Switch (Sustainable Water Management in the city of the future).

6. Cofie, O., Oiubenga, A., Amoah, P. 2010. Introducing urine as an alternative fertilizer source for urban agriculture. Case Studies from Nigeria and Ghana. Urban Agriculture Magazine, Number 23.

7. Drangert, J., Nawab, B. 2010. A cultural-spatial analysis of excreting, recirculation of human excreta and health - The case of North West Frontier Province, Pakistan. Health \& Place 17:57-66.

8. Duncker, LC., Matsebe, GN., Moilwa, N. 2007. The social/cultural acceptability of using human excreta (faeces and urine) for food production in rural settlements in South Africa. Report to the Water Research Commission.

9. Duncker, L.C., Matsebe, G.N. 2008. Prejudices and attitudes toward reuse of nutrients from urine diversion toilets in South Africa. Refereed Paper. 33rd Wedc International Conference, Accra, Ghana, 2008. Access to sanitation and safe water: Global Partnerships and local actions.

10. Flavel, T.C., Murphy D.V. 2006. Carbon and Nitrogen mineralization rates after application of organic amendments to soil. Journal of Environmental Quality, 35: 183-193.

11. Germer, J., Addai, S., Sauerborn, J. 2011. Response of grain sorghum to fertilisation with human urine. Field Crops Research 122: 234-241. 
12. Heinonen-Tanski, H., Wijk-Sijbesma, C. 2004. Human excreta for plant production. Bioresource Technology 96: 403-411.

13. Hoglund, C. 2001. Evaluation of microbial health risks associated with the reuse of source separated human urine. PhD dis., Royal Institute of Technology Stockholm Sweden.

14. Hoglund, C., Ashbolt, N., Stenstrom, T.A., Svensson, L. 2002. Viral persistence in source-separated human urine. Advances in Environmental Research 6: 265-275.

15. Jensen, P.K.M, Phuc, P.D., Knudsen, L.G., Dalsgaard, A., Konradsen, F., Konradsen, F. 2007. Hygiene versus fertilizer: The use of human excreta in agriculture $-\mathrm{A}$ Vietnamese example. Int. J. Hyg. Environ. Health 211: $432-439$.

16. Karak, T., Bhattacharyya, P. 2011. Human urine as a source of alternative natural fertilizer in Agriculture: A Flight of fancy or an achievable Reality. Resources, Conservation and Recycling, 55: 400-408.

17. Lamichhane, M.K., Roger, W., Babcock, J.R. 2012. Survey of attitudes and perceptions of urine diverting toilets and human waste recycling in Hawaii. Sci Total Environ. 2013 Jan 15; 749-756. Doi: 10.1016/J.Scitotenv.2012.11.039. Epub 2012 Dec 8

18. Mariwah, S., Drangert, J.O. 2011. Community perceptions of human excreta as fertilizer in Peri-urban agriculture in Ghana. Waste Management Resources; 29(8):815-822. Pmid: 21242178 Pubmed - Indexed For Medline.

19. Duncker LC. Ownership and use of urine diversion sanitation systems in South Africa. CSIR research report No. CSIR/BE/IPDS/IR/2006/0049/B. Pretoria, South Africa. 2006.

20. Duncker LC, Matsebe GN. Prejudices and attitudes toward reuse of nutrients from urine diversion toilets in South Africa. Refereed Paper. $33^{\text {rd }}$ Wedc International Conference, Accra, Ghana, 2008. Access to sanitation and safe water: Global Partnerships and local actions. 2008.

21. Cofie, O., Adeoti, A., Nkansah-Boadu, F., Awuah, E. Farmers' perception and economic benefits of excreta use in Southern Ghana. Resources, Conservation and Recycling. 2010, 55, $161-166$.

22. Cofie O, Amoah P, Egyir I, Noah A, Tettey-Lowor F. Demonstration on the use of urine in urban agriculture. Sixth Framework Program (2002-2006). 018530 - Switch (Sustainable Water Management in the city of the future). 2011.

23. Benoit N. 2012. Individual's perceptions and the potential of urine as a fertilizer in Ethekwini, South Africa. Unpublished Masters Diss., University of KwaZulu Natal.

24. Drangert J, Nawab B. 2010. A cultural-spatial analysis of excreting, recirculation of human excreta and health - The case of North West Frontier Province, Pakistan. Health \& Place. 2010, 17, 57-66.

25. Lamichhane MK, Roger W, Babcock JR. 2012. Survey of attitudes and perceptions of urine diverting toilets and human waste recycling in Hawaii. Science of Total Environment. 2013 Jan 15; 749-756. Doi: 10.1016/J.Scitotenv. 2012.11.039. Epub 2012 Dec 8. 